\title{
Rostrum of the Corpus Callosum
}

National Cancer Institute

\section{Source}

National Cancer Institute. Rostrum of the Corpus Callosum. NCI Thesaurus. Code C33496.

The anterior-inferior aspect of the corpus callosum, which projects posteriorly and inferiorly from the genu, and which is continuous with the lamina terminalis. 